\title{
Endothelin-1-induced constriction in the coronary resistance vessels and abdominal aorta of the guinea pig
}

\author{
Anne Folta ${ }^{1}$, Irving G. Joshua ${ }^{2}$, and R. Clinton Webb ${ }^{1}$ \\ ${ }^{1}$ Department of Physiology, University of Michigan, Ann Arbor, MI 48109 \\ 2Department of Physiology, University of Louisville, Louisville, KY 40292
}

Summary. The purpose of this study was to examine contractile properties of endothelin-1, a newly discovered vasoactive peptide, in guinea pig coronary resistance vessels and abdominal aorta. Changes in perfusion pressure after injections of endothelin-1 were measured using a constant-flow modified Langendorff preparation. The $\mathrm{ED}_{10}$ values of coronary perfusion pressure were about 100 -fold less for endothelin-1 than for prostaglan$\operatorname{din} F_{2 \alpha}$. After the endothelium was damaged by exposure to free radicals, maximal coronary constriction in response to endothelin- 1 ( $10^{-9}$ moles) was not altered, whereas dilator responses to low doses of endothelin-1 were converted to constrictor responses. Removal of the endothelium from aortic rings significantly increased responsiveness to endothelin- 1 and the maximal response to the peptide. In calcium-free medium, endothelin-1 induced small increases both in perfusion pressure in coronary vessels and in tension in the aorta. Reintroduction of calcium in the coronary and aortic preparations produced a rapid increase in perfusion pressure and tension, respectively. Further, endothelin-1-induced coronary constriction was inhibited $59 \% \pm 7 \%$ by nifedipine $\left(10^{-7}\right.$ moles). We conclude that endothelin-1 is a more potent constrictor than prostaglandin $\mathrm{F}_{2 \alpha}$ in the coronary vasculature. Endothelin-1-induced constriction in the coronary vasculature of the guinea pig is not mediated through an endogenous constricting factor released from the endothelium or a constrictor prostaglandin. Further, endothelin-1-induced dilation in the coronary vasculature and attenuation of endothelin-1-induced

Correspondence: R. Clinton Webb

Received August 8, 1989; revision received January 5, 1990; accepted February 23, 1990. contraction in the abdominal aorta of the guinea pig are mediated through the release of a factor from the endothelium. Endothelin-1-induced coronary constriction and abdominal aortic contraction require extracellular calcium, entering, in part, through nifedipine-sensitive channels.

Key words: Calcium - Nifedipine - Vascular endothelium

Endothelin-1, a newly discovered endotheliumderived vasoactive factor [1], has potent in vitro contractile properties in dog [2] and pig [3] coronary vessels and in rat [4] and rabbit $[5,6]$ aorta, as well as potent in vivo pressor effects in the guinea pig [7]. The mechanisms through which contraction is induced involve the mobilization of extracellular calcium [8], release of intracellular calcium [5], and activation of nifedipine-sensitive calcium channels and nonspecific calcium channels [9]. Yanagasawa et al. [1] first hypothesized that endothelin-1 was an endogenous calcium channel agonist, based on the absence of contraction of porcine coronary artery in calcium-free medium and inhibition of contraction by nifedipine. Since that time, investigators have found that an increase in perfusion pressure or tension was $[8,10,11]$ or was not $[9,12]$ observed in calcium-free medium. Further, reports indicate that calcium channel blockers inhibit $[6,12]$, but do not abolish, endothelin-1-induced constriction or that they have little inhibitory effect [4]. In a recent review, Masaki [13] reported that endothelin-1 working as a calcium channel agonist is a hypothesis which has not been substantiated by the current literature.

The present study was undertaken to evaluate 
the contractile properties of endothelin-1 in guinea pig coronary resistance vessels and abdominal aorta. Whether endothelin-1-induced constriction and contraction are endothelium- or calcium-dependent also was examined.

\section{Materials and methods}

Male guinea pigs $(n=15)$ weighing approximately $350 \mathrm{~g}$ were used in this study. Animals had free access to food and water and were group-housed in light-cycled (0600-1800) temperature-controlled quarters.

Two types of physiologic measurements were investigated: (1) perfusion pressure in the coronary vasculature using a modified Langendorff procedure, and (2) force generation in isolated abdominal aortic rings. For coronary vascular perfusion experiments, guinea pigs were given 300 units of intraperitoneal heparin and killed by a single blow to the head while under anesthesia (ketamine, $40 \mathrm{mg} / \mathrm{kg}$ and xylazine, 6 $\mathrm{mg} / \mathrm{kg}$ ). The chest was opened and the heart arrested in situ by a $4 \mathrm{ml}$ injection of iced $16 \mathrm{mM} \mathrm{KCl}$ into the inferior vena cava. The heart was then rapidly excised and the ascending aorta cannulated with polyethylene tubing. The coronary vasculature was perfused at a constant flow rate with a buffer containing the following (mmol/l): $\mathrm{NaCl} 105.6, \mathrm{KCl} 14.8$, $\mathrm{MgSO}_{4} \cdot 7 \mathrm{H}_{2} \mathrm{O} 1.1, \mathrm{KH}_{2} \mathrm{PO}_{4} 1.2, \mathrm{NaHCO}_{3} 25.0$, dextrose 11.0 , and $\mathrm{CaCl}_{2} \cdot 2 \mathrm{H}_{2} \mathrm{O} 1.25$. The perfusion medium was maintained at $37^{\circ} \mathrm{C}$ and aerated with a mixture of $95 \% \mathrm{O}_{2}$ and $5 \% \mathrm{CO}_{2}$. The heart was allowed to equilibrate for at least 20 min prior to the initiation of the experiment. The flow rate was adjusted to a level necessary to generate an initial perfusion pressure of $25 \mathrm{mmHg}$. The average coronary flow rate was $4 \pm 1 \mathrm{ml} / \mathrm{min}$. Agents were injected $1 \mathrm{~cm}$ above the heart in $0.1 \mathrm{ml}$ amounts using a 1 second bolus technique at $4 \mathrm{~min}$ intervals. Changes in perfusion pressure were measured using a transducer via a $t$-tube between the flow pump and the heart, and recorded on a Grass polygraph.

Following the equilibration period, the coronary vasculature was made to constrict to a bolus injection of prostaglan$\operatorname{din} \mathrm{F}_{2 \alpha}\left(\mathrm{PGF}_{2 \alpha}, \mathbf{1 0}^{-7}\right.$ moles). Subsequent to this treatment, coronary vascular tone stabilized at a level that was approximately $20 \mathrm{mmHg}$ above the initial perfusion pressure. Responsiveness to endothelin-1 $\left(10^{-14}-10^{-9}\right.$ moles $)$ was characterized on this background of coronary vascular tone. In another set of experiments, disruption of the endothelium was achieved by exposing the vessels to free radicals generated by electrolysis of the buffer solution [14]. The perfusate was stimulated by platinum wire electrodes within the tubing cannulating the ascending aorta $2 \mathrm{~cm}$ above the suspended heart. A $9 \mathrm{~V}$ stimulus was delivered as a train of square waves of $2 \mathrm{~ms}$ pulse duration at a frequency of $4 \mathrm{~Hz}$ for $5 \mathrm{~min}$. Changes in perfusion pressure were measured before and after endothelium damage. The absence of dilation to acetylcholine was used to demonstrate endothelium damage. After endothelium damage, dose-response curves to endothelin-1 $\left(10^{-14}-10^{-9}\right.$ moles) were obtained. In another set of experiments, responsiveness to endothelin- $1\left(10^{-9}\right.$ moles $)$ was measured after perfusion of the coronary vasculature for $20 \mathrm{~min}$ with calcium-free medium with $1 \mathrm{~m} M$ EGTA, after reintroduction of calcium, and after injection of nifedipine $\left(10^{-7}\right.$ moles). The effect of pretreatment for $30 \mathrm{~min}$ with indomethacin $(14 \mu M)$ on endothelin-1-induced coronary constriction also was determined.

For isolated vascular ring studies, segments of the abdominal aorta were excised and placed in a physiological salt solution (PSS) of the following composition $(\mathrm{mM}): \mathrm{NaCl} 130$, $\mathrm{KCl} 4.7, \mathrm{NaHCO}_{3} 14.9, \mathrm{KH}_{2} \mathrm{PO}_{4} 1.17, \mathrm{CaCl}_{2} 1.6, \mathrm{MgSO}_{4}$ $7 \mathrm{H}_{2} \mathrm{O} 1.17$, dextrose 5.5, and $\mathrm{CaNa}_{2}$ EDTA 0.03 . The vessel segments were cleaned of excess connective tissue and cut into 3-mm ring segments. Two wires were passed through the lumen taking care not to damage the endothelium. The endothelium was removed from some preparations by gently rubbing the endothelial surface. The failure of acetylcholine $(1 \mu M)$ to relax a contraction induced by $\mathrm{PGF}_{2 \alpha}(0.1 \mu M)$ demonstrated the effectiveness of endothelium removal. After the rings were mounted in the bath, a passive tension of 2 $\mathrm{g}$ was applied to each ring and isometric tension was measured with a force transducer. The PSS in the tissue bath was aerated with $95 \% \mathrm{O}_{2}$ and $5 \% \mathrm{CO}_{2}$ and maintained at a temperature of $37^{\circ} \mathrm{C}$. The aortic rings were allowed to equilibrate for $60 \mathrm{~min}$ before the experiment.

Initial studies involved quantitating responses of intact and denuded aortic rings to increasing bath concentrations of endothelin-1 $\left(10^{-11}-3 \times 10^{-8} M\right)$. Responses to each concentration were observed for $10 \mathrm{~min}$ before the bath concentration of endothelin-1 was increased 3-fold. In a second series of experiments, we observed the response to endothelin-1 in the absence of extracellular calcium. Aortic rings were exposed to a calcium-free PSS containing $1 \mathrm{~m} M$ EGTA for 2 min prior to exposure to $10^{-8} M$ endothelin-1. After a 10-min exposure period, calcium was reintroduced to provide an effective concentration of $1.6 \mathrm{mM}$. The response to endothelin-1 was observed for an additional 20 min.

Synthetic human/porcine endothelin-1 (Peptides International, Louisville, KY, USA) was mixed with distilled water to obtain concentrations of $10^{-5} \mathrm{M}$. Serial dilutions were performed using either PSS or distilled water. Acetylcholine (Miochol, IOLAB Pharmaceuticals, Claremont, CA, USA) and prostaglandin $\mathrm{F}_{2 \alpha}$ (Sigma, St. Louis, MO, USA) were diluted in PSS and prepared daily. Nifedipine (Sigma) was dissolved in ethanol, and indomethacin was dissolved in $100 \mathrm{mM} \mathrm{NaCO}$. Data are reported as means \pm standard error of the means (SEM). An unpaired analysis (Student's $t$-test) was used to compare observations between the control and treated groups. The Bonferroni correction was used when multiple comparisons were made. A $P$ value of 0.05 was considered statistically significant. $\mathrm{ED}_{50}$ values (dose of endothelin-1 that caused a half-maximal response in aorta) and $E D_{10}$ values (dose of endothelin-1 that caused a 10 $\mathrm{mmHg}$ change in perfusion pressure in the coronary vasculature) were estimated from graphic representations of the data.

\section{Results}

Coronary vasodilation was observed in response to low doses of endothelin-1 $\left(10^{-14}-10^{-12}\right.$ moles) in the intact preparation (Fig. 1). A biphasic response, initial dilation followed by constriction, was observed at a dose of $10^{-11}$ moles in 2 out of 5 animals. Higher doses of endothelin-1 $\left(10^{-10}\right.$ and $10^{-9}$ moles) induced only increases in perfusion pressure in all animals in a dose-dependent fashion. Constrictor responses in the coronary vasculature were of slow onset and long lasting. The maximal constriction in response to endothelin-1 $\left(10^{-9}\right.$ moles) occurred between 5 and $30 \mathrm{~min}$ after injection. Following the final dose of 


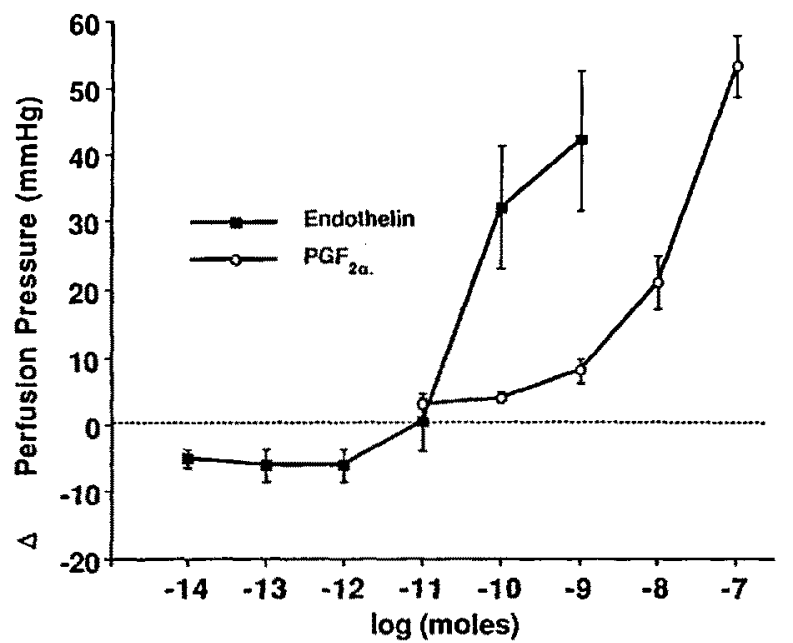

Fig. 1. Dose-response curves to prostaglandin $F_{2 \alpha}$ and endothelin-1 in the coronary resistance vessels $(n=5)$. Values are means \pm standard error of mean

endothelin-1, the coronary vasculature was perfused with normal PSS. The increased tone in the vessels was only reduced $67 \%$ and did not return to baseline levels even after continuous perfusion for $1 \mathrm{~h}$ with fresh PSS. Endothelin-1 has a more potent effect in inducing coronary constriction than did prostaglandin $\mathrm{F}_{2 \alpha}$ (Fig. 1), in that the threshold dose which resulted in a $10 \mathrm{mmHg}$ increase in perfusion pressure was almost 100 fold lower for endothelin-1 than for $\mathrm{PGF}_{2 \alpha}$ [endothelin-1, $-\log \mathrm{ED}_{10}$ value $=10.58 \pm 0.18$ (antilog $=2.6 \times 10^{-11}$ moles); prostaglandin $F_{2 \alpha}$, $-\log E D_{10}$ value $=8.73 \pm 0.25\left(\right.$ antilog $1.8 \times 10^{-9}$ moles); $P<0.05]$.

Dilator responses to injections of acetylcholine $10^{-7}$ moles), before electrical stimulation of the buffer, were converted to constrictor responses after stimulation (perfusion pressure response before, $-15 \pm 3 \mathrm{mmHg}$; and after, $10 \pm 3 \mathrm{mmHg}$; $P<0.05$ ), indicating that the endothelium had been damaged. After damaging the endothelium, dilator responses to low doses of endothelin-1 were converted to constrictor responses [15] and the $E_{10}$ values were significantly lower [damaged, $-\log \quad \mathrm{ED}_{10} \quad$ value $=11.67 \pm 0.2$ (antilog $=2.1 \times 10^{-12}$ moles); intact, $-\log \mathrm{ED}_{10}$ value $=10.58 \pm 0.18$ (antilog $=2.6 \times 10^{-11}$ moles); $P<0.05]$ but the magnitude of endothelin-1induced constriction at $10^{-10}$ and $10^{-9}$ moles was not changed (Fig. 2). Pretreatment of the coronary vasculature for $30 \mathrm{~min}$ with indomethacin (14 $\mu M$ ) did not significantly alter constrictor responses to endothelin-1 (indomethacin treatment, $57 \pm 3 \mathrm{mmHg}$; intact untreated, $42 \pm 11 \mathrm{mmHg}$ ).

The protocol used to examine the calcium dependency of the endothelin-1-induced constriction in the coronary circulation is shown in a representative tracing (Fig. 3). Endothelin-1 (10-9 moles) produced a large increase in perfusion pressure in the presence of $1.25 \mathrm{~m} M$ calcium in the perfusate. After coronary perfusion with calciumfree medium with $1 \mathrm{mM}$ EGTA for $20 \mathrm{~min}$, the endothelin-1-induced constriction was significantly reduced. Subsequent reintroduction of calcium (1.25 $\mathrm{m} M$ ) into the perfusate led to immediate increases in perfusion pressure. Cumulative observations of coronary endothelin-1-induced constriction in calcium PSS $(1.25 \mathrm{mM})$, in calciumfree PSS with $1 \mathrm{~m} M$ EGTA, after readdition of calcium, and after nifedipine inhibition are shown in Fig. 3. Compared to responses in perfusate with calcium $(1.25 \mathrm{mM})$, responses in calcium-free solution were reduced $(15 \%$ of the maximum re-

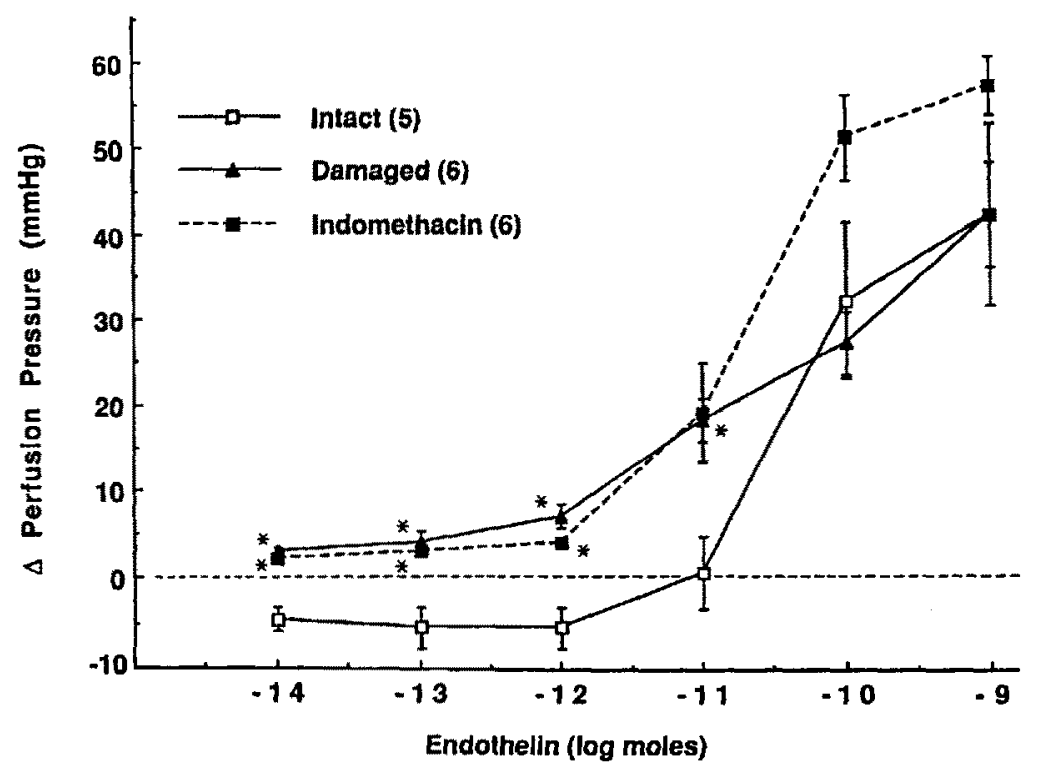

Fig. 2. Cumulative results of coronary vascular responsiveness to endothelin-1 in the presence of an intact endothelium, after endothelium damage, and after indomethacin treatment. The number of animals is indicated parenthetically. Asterisks indicate statistically significant $(P<0.05)$ differences compared to the intact preparation. Values are means \pm standard error of mean 


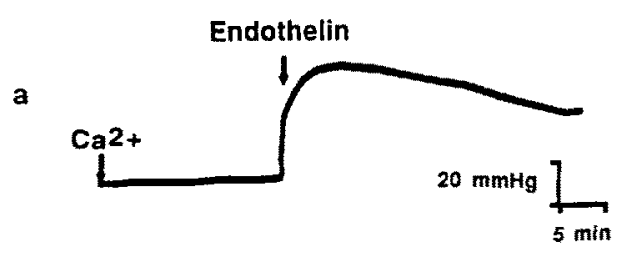

b

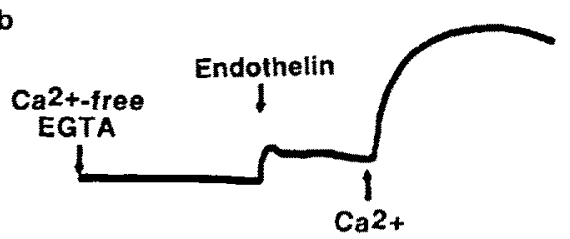

c

Calcium (1.25 mM)

Calcium-free, 1 mM EGTA

$\square$ Readdition of Calcium

Nifedipine $\left(10^{-7}\right.$ moles)

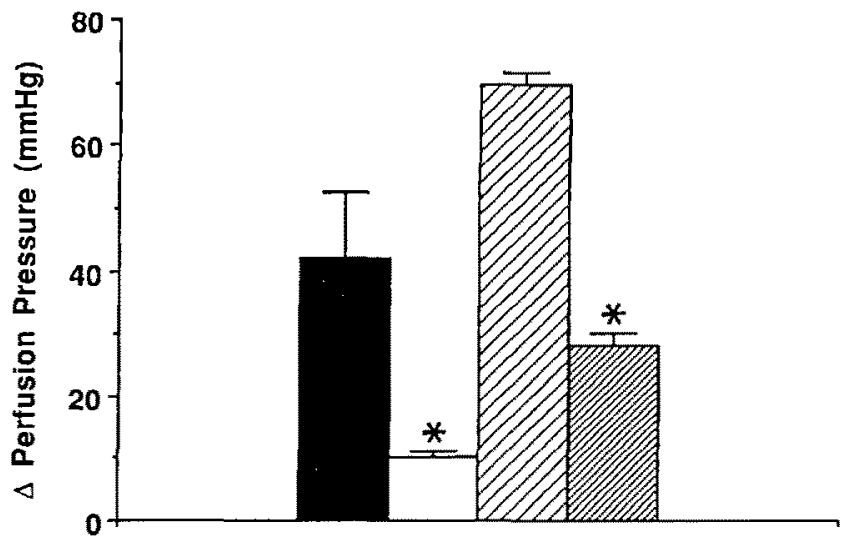

Fig. 3. a. Representative tracings of coronary constriction to endothelin-1 $\left(10^{-9}\right.$ moles in the presence of $1.25 \mathrm{mM}$ calcium in the perfusate. b Effect of endothelin-1 injection after coronary vessel perfusion for $20 \mathrm{~min}$ with calcium-free medium with $1 \mathrm{~m} M$ EGTA, and after reintroduction of calcium $(1.25 \mathrm{~m} M)$ into the perfusate. c Cumulative results of coronary vascular constriction to endothelin-1 $\left(10^{-9}\right.$ moles in the presence of $1.25 \mathrm{~m} M$ calcium, reduction of perfusion pressure in the absence of extracellular calcium, endothelin1-induced constriction after reintroduction of calcium into the perfusate, and nifedipine inhibition of the constriction. Asterisks indicate statistically significant $(P<0.05)$ reduction in perfusion pressure in calcium-free medium and significant $(P<0.005)$ inhibition by nifedipine. Values are means \pm standard error of mean for 4-5 animals

sponse to endothelin-1 in the presence of calcium). After reintroduction of calcium into the perfusate, endothelin-1-induced increases in perfusion pressure were enhanced $(70 \pm 2 \mathrm{mmHg})$, but not significantly, as compared to responses observed in experiments where the calcium level was not manipulated ( $42 \pm 11 \mathrm{mmHg}$ ). The constriction in response to endothelin-1 observed after the reintroduction of calcium was inhibited $59 \% \pm 7 \%$ by injection of nifedipine $\left(10^{-7}\right.$ moles).

Endothelin-1 caused a dose-dependent contraction of abdominal aortic rings which was slow in

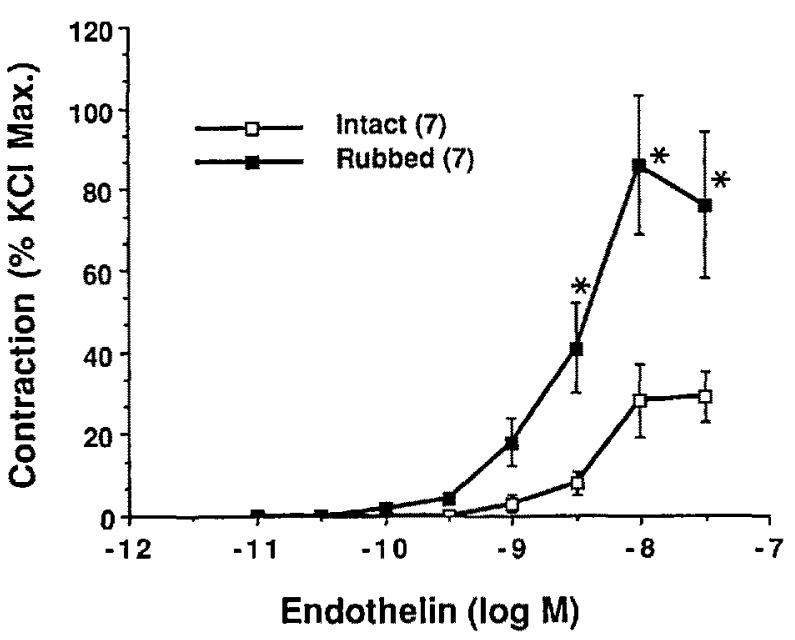

Fig. 4. Contraction of the abdominal aorta induced by endothelin-1 in rings with intact or rubbed endothelium. $E D_{50}$ values were significantly reduced in the rubbed preparation. The number of animals is indicated parenthetically. Asterisks indicate statistically significant $(P<0.05)$ differences between the intact and rubbed preparations

onset, in that maximal responses occurred after 4$5 \mathrm{~min}$. After washing the rings for $30 \mathrm{~min}$ with PSS, $50 \%$ of the contraction was still present. Figure 4 illustrates that the endothelin-1-induced contraction in the intact abdominal aorta was about $30 \%$ of the maximal contraction to $\mathrm{KCl}$.

Relaxation responses to acetylcholine $\left(10^{-6} \mathrm{M}\right)$ were significantly less in rubbed rings $(3 \% \pm 4 \%$ of the response to prostaglandin $\mathrm{F}_{2 \alpha}$ ) as compared to intact rings $(77 \% \pm 7 \%)$, indicating that the endothelium had been sufficiently removed by rubbing. Responses to endothelin- 1 were potentiated following removal of the endothelium. $E D_{50}$ values to endothelin-1 were increased significantly following endothelium removal $\left(-\log E_{50}=\right.$ $8.60 \pm 0.08 ;$ antilog $\left.=2.5 \times 10^{-9} M\right)$ compared to $E_{50}$ values for intact rings ( $-\log E_{50}=$ $8.23 \pm 0.08$; antilog, $5.9 \times 10^{-9} M$ ). Maximal responses to endothelin-1 also were significantly increased following endothelium removal. Maximal $\mathrm{KCl}$-induced contractions were not significantly different for the intact $(702 \pm 125 \mathrm{mg}$ force/ $\mathrm{mg}$ tissue) as compared to the rubbed rings (645 $\pm 126 \mathrm{mg}$ force/mg tissue).

Endothelin-1 caused contraction of aortic rings incubated in a calcium-free medium (Fig. 5). The magnitude of contraction was approximately $19 \%$ of the maximal response to endothelin- 1 in the presence of calcium. Reintroduction of calcium produced a marked and rapid contraction which was maximal within $5 \mathrm{~min}$ and tended to gradually wane during the remainder of the $20 \mathrm{~min}$ response period. 


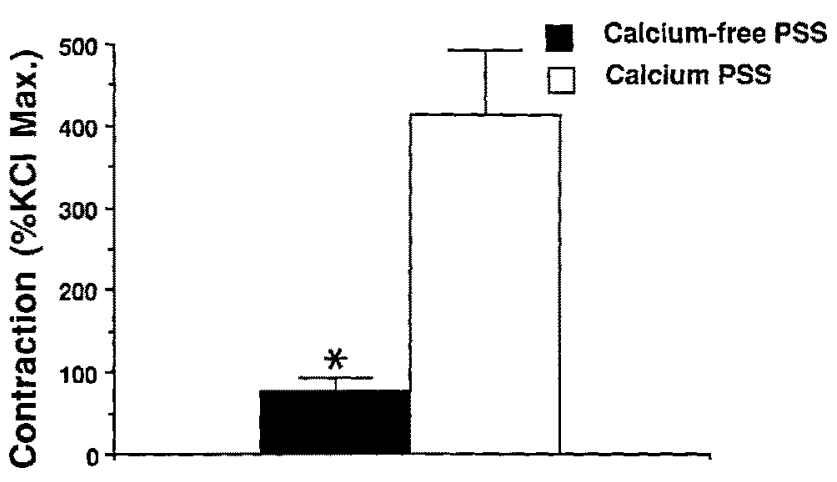

Fig. 5. Cumulative results from experiments in the abdominal aorta showing statistically significant $(P<0.05)$ reductions in tension in calcium-free medium with $1 \mathrm{~m} M$ EGTA, whereas after reintroduction of $1.6 \mathrm{~m} M$ calcium, contraction returned to maximal levels. Values are mean \pm standard error of mean for 8 animals

\section{Discussion}

The present study demonstrates that endothelin-1 is a more potent constrictor than prostaglandin $F_{2 \alpha}$ in the coronary vasculature. Endothelin-1induced contraction in the abdominal aorta was less than that induced by $\mathrm{KCl}$. The magnitude of endothelin-1-induced constriction in the coronary vasculature was not reduced after removal of the endothelium or after indomethacin pretreatment, indicating that the constrictor responses to endothelin-1 are not influenced by the release of an endothelium-derived contracting factor or constrictor prostaglandin. Further, these findings would suggest that it is unlikely that synthetic exogenous endothelin-1 stimulates the release of endogenous endothelin (EDCF) from the endothelium in coronary vessels, because if a constricting factor was released, the response would have been enhanced in the presence of an intact endothelium. Likewise, exogenous endothelin-1 is not likely to stimulate the release of the constrictor, thromboxane, a phenomenon which occurs in guinea pig lung [16]. The magnitude of endothelin1 -induced contraction in the abdominal aorta was not reduced, but enhanced after endothelium removal. These findings are in agreement with Auguet et al. [11] and Saito et al. [12], who reported small shifts to the left of the endothelin-1 dose-response curve after endothelium removal in arterial ring preparations. These findings suggest that in the abdominal aorta, endothelin-1 does not stimulate release of a contracting factor from the endothelium, but may stimulate the release of a dilator factor, possibly endothelium-derived relaxing factor (EDRF). In the rat mesentery [17], this dilator factor may be prostacyclin, but it is not a prostaglandin in the abdominal aorta of the guinea pig [15].

Endothelin-1 induced dilation in the coronary vasculature was endothelium-dependent [15]. This dependence was first reported by Warner, de Nucci, and Vane [18] who used rat endothelin in isolated perfused rat mesentery where oxyhemoglobin blocked endothelin-3-induced dilation. These findings suggest that endothelin-3induced dilation occurs through stimulated release of endothelium-derived relaxing factor. In the present study, low doses of endothelin-1 did not induce relaxation in the abdominal aorta that had no resting tone. In another set of experiments, we observed relaxation after initially contracting the rings by adding prostaglandin $\mathrm{F}_{2 \alpha}$ to the bath [15]. Observations of constrictor as well as dilator responses suggest that endothelin-1 may play a modulating role in the local control of vascular tone.

In calcium-free buffer with $1 \mathrm{~m} M$ EGTA, coronary perfusion pressure increased to $15 \%$, and abdominal aortic ring tension increased to $19 \%$, of the maximal response to endothelin-1 in the presence of calcium. Our findings are in agreement with Sugiura et al. [8] who found that $20 \%$ $30 \%$ of the maximum contraction in rabbit aortic strips remained after calcium-free incubation with $1 \mathrm{~m} M$ EGTA for 20-60 min. Similarly, Auguet et al. [11] found that a slow and sustained contraction (29\% of the phenylephrine response in control medium) was induced after calcium-free treatment for $20 \mathrm{~min}$. In mesenteric resistance vessels, Wallnofer et al. [10] reported that endothelin-1induced contraction in calcium-free medium reached $11 \%$ of the magnitude of norepinephrine contraction in normal PSS. In contrast to these studies, Van Renterghem et al. [9] in rat aortic strips with EGTA, and Saito et al. [12] in cat cerebral rings without EGTA, reported no contractile response of vessels to endothelin- 1 in calcium-free medium. For unknown reasons, we found an exaggerated constrictor response above control values after reintroduction of calcium. Also in the present study, endothelin-1-induced constriction in the coronary vasculature was inhibited $59 \%$ by nifedipine $\left(10^{-7}\right.$ moles). Similarly, Watanabe et al. [6] found that doses of nifedipine up to $10^{-5} \mathrm{M}$ inhibited $40 \%$ of the contraction induced by endothelin-1 $\left(10^{-7} \mathrm{M}\right)$ in rabbit aortic rings. In contrast to these studies, Auguet et al. [11] found that nifedipine, diltiazem, and D-600 had almost no effect in inhibiting endothelin-1-induced contraction in rat aortic rings. Recently, studies using rabbit aortic smooth muscle cells have reported that the initial peak in intracellular calcium levels is related to the release of calcium from intracellular stores, whereas the plateau or sustained phase 
is related to the entrance of extracellular calcium [5]. Since only about half of the endothelin1 -induced coronary constriction is inhibited by nifedipine, our findings suggest that the receptoroperated calcium channels, leak channels, nonspecific cation channels, or sustained intracellular calcium release must be instrumental in mediating the long-lasting effects of endothelin-1.

In conclusion, our results indicate that endothelin-1-induced constriction in the coronary vasculature of the guinea pig is not mediated through an endogenous constricting factor released from the endothelium, or by a constrictor prostaglandin. Further, endothelin-1-induced dilation in the coronary vasculature and attenuation of the endothelin-1-induced contraction in the abdominal aorta in the guinea pig are mediated through release of a factor from the endothelium. It is not known why coronary constriction was not enhanced after endothelium damage, as was the case in the aorta after endothelium removal. Endothelin-1-induced coronary constriction and abdominal aortic contraction require extracellular calcium; entering, in part, through nifedipinesensitive channels.

Acknowledgments. This work was supported by NIH grants HL27020 and HL18575 and a Biomedical Research Grant, The University of Michigan. Dr. Folta is a recipient of a National Research Service Award (NR 05894-04). Dr. Joshua is an Established Investigator of the American Heart Association.

\section{References}

1. Yanagasawa $M$, Kurihara $H$, Kimura $S$, Tomobe $Y$, Kobayashi M, Mitsui Y, Yazaki Y, Goto K, Masaki T (1988) A novel potent vasoconstrictor peptide produced by vascular endothelial cells. Nature 332: 411-415

2. Pang DC, Johns A, Patterson K, Parker-Botelho LH, Rubanyi G (1989) Endothelin-1 stimulates phosphatidylinositol hydrolysis calcium uptake in isolated canine coronary arteries. J Cardiovasc Pharmacol 13: S75-S79

3. Stasch JP, Kazda S (1989) Endothelin-1-induced vascular contractions: interactions with drugs affecting the calcium channel. J Cardiovasc Pharmacol 13: S63-S66

4. Chabrier PE, Auguet $M$, Roubert $P$, Lonchampt MO, Gillard V, Guillon J, Delaflotte S, Braquet P (1989) Vascular mechanism of action of endothelin-1: effect of $\mathrm{Ca}^{2+}$ antagonists. J Cardiovase Pharmacol 13: $332-\mathrm{S} 35$
5. Marsden P, Danthuluri NR, Brenner BM, Ballermann B, Brock TA (1989) Endothelin action on vascular smooth muscle involves inositol trisphosphate and calcium mobilization. Biochem Biophys Res Commun 158: 86-93

6. Watanabe T, Kusumoto K, Kitayoshi T, Shimamoto N (1989) Positive inotropic and vasoconstrictive effects of endothelin-1 in in vivo and in vitro experiments: characteristics and the role of L-type calcium channels. J Cardiovasc Pharmacol 13: S108-S111

7. Li L, Ishikawa T, Miyauchi T, Yanagasawa M, Kimura S, Goto K, Masaki T (1989) Pressor response to endothelin in guinea pigs. Jpn J Pharmacol 49:549-552

8. Sugiura M, Inagami T, Hare GMT, Johns JA (1989) Endothelin action: inhibition by a protein kinase $C$ inhibitor and involvement of phosphoinositols. Biochem Biophys Res Commun 158: 170-176

9. Van Renterghem C, Vigne P, Barhanin J, SchmidAlliana A, Frelin C, Lazdunski M (1988) Molecular mechanism of action of the vasoconstrictor peptide endothelin. Biochem Biophys Res Commun 157: 977-985

10. Wallnofer A, Weir S, Ruegg U, Cauvin C (1989) The mechanism of action of endothelin-1 compared with other agonists in vascular smooth muscle. J Cardiovasc Pharmacol 13: S23-\$31

11. Auguet M, Delaflotte S, Chabrier PE, Pirotzky E, Clostre $F$, Braquet $P(1988)$ Endothelin and $\mathrm{Ca}^{2+}$ agonist Bay $\mathrm{K}$ 8644: different vasoconstrictive properties. Biochem Biophys Res Commun 156: 186-192

12. Saito A, Shiba R, Kimura S, Yanagasawa M, Goto K, Masaki T (1989) Vasoconstrictor response of large cerebral arteries of cats to endothelin, an endotheliumderived vasoactive peptide. Eur J Pharmacol 162:353358

13. Masaki T (1989) The discovery, the present state, and the future prospects of endothelin. J Cardiovasc Pharmacol 13: $\mathrm{S} 1-\mathrm{S} 4$

14. Lamb FS, King CM, Harrell K, Burkel W, Webb RC (1987) Free radical-mediated endothelial damage in blood vessels after electrical stimulation. Am J Physiol 21: H1041-H1046

15. Folta A, Joshua IG, Webb RC (1989) Dilator actions of endothelin in coronary resistance vessels and the abdominal aorta of the guinea pig. Life Sci 45:2627-2635

16. de Nucci $G$, Thomas R, D'Orleans-Juste P, Antunes E, Walder C, Warner T, Vane J (1988) Pressor effects of circulating endothelin are limited by its removal in the pulmonary circulation and by the release of prostacyclin and endothelium-derived relaxing factor. Proc Natl Acad Sci USA 85: 9797-9800

17. Rakugi H, Nakamaru $M$, Tabuchi $Y$, Nagano $M$, Mikami H, Ogihara T (1989) Endothelin stimulates the release of prostacyclin from rat mesenteric arteries. Biochem Biophys Res Commun 160:924-928

18. Warner T, de Nucci G, Vane J (1989) Rat endothelin is a vasodilator in the isolated perfused mesentery of the rat. Eur J Pharmacol 159: 325-326 